\title{
The Effects of Local Anaesthetics on QT Parameters during Thoracic Epidural Anaesthesia Combined with General Anaesthesia: Ropivacaine versus Bupivacaine
}

\author{
Özlem Güven'1, Hilal Sazak', Ali Alagöz', Eser Şavkılıoğlu', Çilsem Sevgen Demirbaş', Ali Yıldız², Erdem Karabulut ${ }^{3}$
}

${ }^{1}$ Department of Anesthesiology and Reanimation, Atatürk Chest Diseases and Thoracic Surgery Education and Research Hospital, Ankara, Turkey

${ }^{2}$ Department of Cardiology, Harran University Faculty of Medicine, Şanlıurfa, Turkey

${ }^{3}$ Department of Biostatistics, Hacettepe University Faculty of Medicine, Ankara, Turkey

\begin{abstract}
Background: Many studies focusing on the effects of local anaesthetics on QT intervals have been performed, but the articles evaluating the relationship between thoracic epidural anaesthesia combined with general anaesthesia and QT parameters are very limited.

Aims: We aimed to compare the effects of bupivacaine and ropivacaine on QT interval, corrected QT, dispersion of QT, and corrected dispersion of QT in patients undergoing lung resection under thoracic epidural anaesthesia combined with general anaesthesia.

Study Design: Prospective clinical study.

Methods: Thirty ASA physical status 1-3 patients requiring thoracic epidural anaesthesia combined with general anaesthesia for thoracic surgery. Patients were randomly assigned to two groups, which were allocated to receive either bupivacaine (Group B) or ropivacaine (Group R) during thoracic epidural anaesthesia. Following haemodynamic monitoring, a thoracic epidural catheter was inserted. Local anaesthetic at an average dose of $1.5 \mathrm{~mL} /$ segment was given through an epidural catheter. The same general anaesthesia protocol was administered in both groups. Records and measurements were performed on 10 phases that were between the thoracic epidural catheter insertion to the $5^{\text {th }}$ min of endobronchial intubation. In all phases, systolic arterial pressure, diastolic arterial pressure, mean arterial pressure, heart rate, peripheral $\mathrm{O}_{2}$ saturation, and electrocardiogram monitoring were performed in patients. All QT parameters were recorded by 12-lead electrocardiogram and analysed manually by a cardiologist.
\end{abstract}

Results: QT intervals were similar between two groups. In Group R, corrected QT values at the $20^{\text {th }}$ min of local anaesthetic injection and the $5^{\text {th }}$ min of endobronchial intubation were shorter than those in Group B $(p<0.05)$. The basal dispersion of QT and dispersion of QT values at the $1^{\text {st }}$ min of propofol injection were shorter than those in Group R $(p<0.05)$. The corrected dispersion of QT value at the $1^{\text {st }}$ min of propofol injection was shorter in Group R $(p<0.05)$. In Group $R$, the decrease in mean arterial pressure at the $1^{\text {st }}$ min of fentanyl injection was significant compared with $G r o u p ~ B(p<0.05)$. There was no significant difference between the groups with respect to heart rate and complications.

Conclusion: The corrected QT, dispersion of QT, and corrected dispersion of QT intervals were slightly longer in the patients receiving bupivacaine compared with those receiving ropivacaine in various phases of the present study.

Key Words: Bupivacaine, ropivacaine, QT parameters, thoracic epidural anaesthesia, local anaesthetics

Received: 24.04.2013

Accepted: 03.10.2013

\section{Introduction}

Thoracic epidural anaesthesia (TEA) combined with general anaesthesia (GA) can improve the outcome of patients undergoing lung surgery $(1,2)$. TEA reduces cardiac and splanchnic sympathetic activity and thereby influences perioperative function of vital organ systems (3). In spite of the most severe complication of cardiotoxicity, long-acting local anaesthetics (LAs) (4) are the most common drugs for intraoperative and postoperative pain management, combined with or without opioids (5). Studies have shown that ropivacaine has a wider margin of safety compared with bupivacaine $(5,6)$. The OT interval, which is important for ventricular conduction is measured from the beginning of the QRS complex to the end of the T wave. It represents the total time for ventricle depolarisation and repolarisation. Although ropivacaine and bupivacaine were reported to cause a prolonged QT interval due to inhibition of cardiac sodium channels, ropivacaine was found to be less cardiotoxic than bupivacaine with regard to ventricular conduction (7). The difference in electrophysiological impairment with ropivacaine and bupivacaine could be induced by different binding proteins or different stereoselective inhibition of cardiac sodium channels (8). Takmaz et al. (9) have shown QT interval alterations in patients who received bupivacaine for stellate ganglion blockade. Alterations in conduction in the myocardium (prolongation of the QT interval and QRS widening) were considered as early signs of cardiotoxicity (10). In addition, both congenital and acquired prolongation of the QT interval is considered to be associated with a high incidence of ventricular fibrillation and sudden cardiac death (11).

Though several studies focusing on the effects of LA on the OT interval have been performed, the articles evaluating 
the relationship between TEA combined with GA and QT parameters are very limited $(7,9)$. In the present study, we aimed to compare the effects of bupivacaine and ropivacaine on the QT interval, corrected QT (QTc), dispersion of QT (QTd), and corrected QTd (QTcd) in patients undergoing lung resection under TEA combined with GA. In our study, we particularly focused on the beginning of TEA, induction of GA, and intubation period and an increased incidence of severe haemodynamic alterations.

\section{Materials and methods}

After receiving approval of the institutional review board and after gaining written informed consent from the patients, 30 patients were prospectively enrolled to this study. Patients aged 18 to 61 years, American Society of Anaesthesiologists physical status 1-3, and scheduled for elective lung resection under TEA combined with GA were included in the study. The exclusion criteria were existence of abnormalities of conduction, arrhythmias, treatment with drugs known to prolong QT duration, any cardiac co-morbidities, and contraindication for regional anaesthesia. Patients were randomly divided into two groups, which were allocated to receive either bupivacaine $(0.5 \%)$ (Marcaine ${ }^{\circledR}$, AstraZeneca, İstanbul, Turkey) or ropivacaine $(0.75 \%)$ (Naropin ${ }^{\circledR}$, AstraZeneca, Istanbul,Turkey) during TEA.

In the operating room, systolic arterial pressure (SAP), diastolic arterial pressure (DAP), mean arterial pressure (MAP), heart rate $(\mathrm{HR})$, peripheral $\mathrm{O}_{2}$ saturation $\left(\mathrm{SpO}_{2}\right)$, and electrocardiogram (ECG) monitoring (Siemens SC 8000, Draeger Medical Systems, Danver, USA) were performed in patients without premedication. Twelve-lead ECG was recorded to assess the QT interval. Prior to the TEA procedure, $10 \mathrm{~mL} / \mathrm{kg}$ normal saline was given in all patients.

An epidural catheter (Perifix ${ }^{\circledR}$, Braun, Melsungen, Germany) was inserted through the T6-7 or T7-8 intervertebral space with a median approach using the hanging-drop technique under sterile conditions, and the catheter was advanced $5 \mathrm{~cm}$ to cephalad. A test dose of $3 \mathrm{~mL}$ study drug was administered to exclude unintentional subarachnoid injection in each group. LA boluses, at an average dose of $1.5 \mathrm{~mL} /$ segment, were given through the epidural catheter in order to affect the five included segments. The total dose of LA was calculated based on the age and height of the patients. Sensorial and motor block levels were evaluated by the pin-prick test and Bromage scale. Surgical analgesia level was accepted as T4 dermatome. Epidural LA boluses were repeated every 2 hours during the operation. Fentanyl (Fentanyl Citrate, Abbott Lab. North Chicago, USA), propofol (Propofol \%1 Fresenius Kabi $A B^{\circledR}$, Upsala, Sweden) and vecuronium bromide (Norcuron ${ }^{\circledR}$, Organon, Oss. Holland) were applied for induction of GA. Endobronchial intubation using a left-sided double lumen tube, radial artery cannulation, and central venous cannulation were performed in all patients. In maintenance, sevoflurane (Sevorane ${ }^{\circledR}$, Abbott Lab, North Chicago, USA), fentanyl citrate, and vecuronium bromide were given. The conventional one-lung ventilation procedure was maintained during operations.
The study protocol consisted of 10 phases. The timing of measurements and records were as follows:

1: After the insertion of epidural catheter

2: Immediately after injection of LA

3: 10 min after injection of LA

4: 20 min after injection of LA

5: 1 min after injection of intravenous (i.v.) fentanyl

6: 1 min after injection of i.v. propofol

7: 3 min after injection of i.v. vecuronium

8: During laryngoscopy

9: 1 min after endobronchial intubation with left-sided double lumen tube

10: 5 min after endobronchial intubation with left-sided double lumen tube

In all phases, $\mathrm{SAP}, \mathrm{DAP}, \mathrm{MAP}, \mathrm{HR}$, and $\mathrm{SpO}_{2}$ were collected. QT, QTc, QTd, and QTcd were also recorded by 12-lead ECG and analysed manually by the cardiologist. QT values were determined by calculating average QT intervals on a certain ECG for each phase. QTc values were calculated according to the Bazett formula (QTc=Q-T sec/VRR sec) (12).

The QT differences were calculated by using the longest and the shortest QT values on each ECG for QTd. Similarly, the QTc differences were calculated by using the longest and the shortest QTc values on each ECG for QTcd. Ephedrine (5 $\mathrm{mg})$, atropine $(0.5 \mathrm{mg})$, and lidocaine $(1 \mathrm{mg} / \mathrm{kg})$ were administered and noted in cases of hypotension (30\% decrease in SAP with respect to basal values), bradycardia ( $\mathrm{HR}<50$ beat/ $\mathrm{min})$, and ventricular extrasystoles ( $>6$ beat $/ \mathrm{min}$ ), respectively. The protocol was terminated following the last measurements at the $5^{\text {th }}$ min of intubation.

\section{Statistical analysis}

Statistical analysis was performed using SPSS 11.0 (SPSS, Inc.) for Windows. The results are expressed as mean \pm standard deviation (SD). Student's t-test was used in analysis of demographic data and electrolyte values, whereas Fisher exact test was used to compare the frequency of complications among the two groups. Mann-Whitney $U$ test was applied for comparison between the groups. Friedman test was used to analyse the differences within time. When the differences within time were significant, Wilcoxon's signed rank test with Bonferroni correction was administered. $P$ values of less than 0.05 were considered to be statistically significant.

\section{Results}

There was no significant difference between the groups in terms of age, body weight, height, sex, and the levels of preoperative sodium and calcium $(p>0.05)$. Although the differences in preoperative potassium levels were statistically significant between the groups, all levels were within the normal range $(p<0.05)$ (Table 1$)$.

Compared with basal values, the prolongations of QT intervals at the $3^{\text {rd }}$ min of vecuronium injection and during laryngoscopy were statistically significantly different in both groups $(p<0.001)$. The QT interval also significantly prolonged at the $1^{\text {st }}$ min of propofol injection in Group $R(p<0.001)$. There was no significant difference between the groups in terms of QT interval $(p>0.05)$. 
The prolongation of QTc values during laryngoscopy, and at the $1^{\text {st }} \mathrm{min}$ and the $5^{\text {th }} \mathrm{min}$ of endobronchial intubation was statistically significantly different in Group B, whereas it was only significant during laryngoscopy in Group $R(p<0.05)$. In Group R, the QTc values at the $20^{\text {th }}$ min of LA injection and $5^{\text {th }}$ min of endobronchial intubation were significantly shorter than those in Group B ( $p<0.05)$ (Table 2).

There was no significant difference with respect to the QTd values within the groups. The basal QTd and QTd value at the $1^{\text {st }}$ min of propofol injection were significantly shorter in Group R in comparison with Group B $(p<0.05)$ (Table 3).

There was no statistically significant difference within the groups with respect to the QTcd values. The basal QTcd and QTcd value at the $1^{\text {st }} \mathrm{min}$ of propofol injection were significantly shorter in Group R in comparison with Group B $(p<0.025$ and $p<0.029$, respectively).

In Group B, MAP was lower at the $1^{\text {st }}$ min of propofol injection, $3^{\text {rd }}$ min of vecuronium injection, and $5^{\text {th }}$ min of endobronchial intubation compared with the basal values $(p<0.05)$. In Group R, MAP was lower at the $1^{\text {st }}$ min of fentanyl injection,

Table 1. Patient's characteristics and electrolyte levels. Data are presented as mean \pm standard deviation (SD)

\begin{tabular}{|lccc|}
\hline & $\begin{array}{c}\text { Group B } \\
(\mathbf{n = 1 5})\end{array}$ & $\begin{array}{c}\text { Group R } \\
(\mathbf{n = 1 5 )}\end{array}$ & $\mathbf{p}$ \\
\hline Age (year) & $38.40 \pm 12.08$ & $38.60 \pm 11.35$ & 0.963 \\
Weight (kg) & $64.47 \pm 8.45$ & $66.87 \pm 11.28$ & 0.515 \\
Height (cm) & $166.93 \pm 8.19$ & $169.07 \pm 8.90$ & 0.501 \\
Sex (female/male) & $6 / 9$ & $3 / 12$ & 0.232 \\
Sodium (mEq/L) & $139.00 \pm 2.97$ & $139.67 \pm 3.03$ & 0.840 \\
Potassium (mEq/L) & $4.06 \pm 0.37$ & $4.34 \pm 0.28$ & $0.031 *$ \\
Calcium (mg/dL) & $9.32 \pm 0.53$ & $9.55 \pm 0.57$ & 0.724 \\
\hline${ }^{*}$ < $<0.05:$ Comparison between groups. & & \\
\hline
\end{tabular}

$1^{\text {st }} \min$ of propofol injection, $3^{\text {rd }}$ min of vecuronium injection, and $5^{\text {th }}$ min of endobronchial intubation compared with the basal values $(p<0.05)$. In Group $R$, the decrease in MAP at the $1^{\text {st }}$ min of fentanyl injection was statistically significant compared with Group B $(p<0.05)$.

Compared with the basal values, decreases in HR were significant at the $10^{\text {th }}$ min of LA injection, at the $1^{\text {st }}$ min of propofol injection, and at the $3^{\text {rd }}$ min of vecuronium injection in both groups $(p<0.05)$. There was no significant difference between the groups with respect to HR.

We determined ventricular extrasystoles, which were recovered without medication in one patient, in each group throughout the study. We observed bradycardia, which responded to atropine in one patient in Group B. Hypotension that recovered with ephedrine was recorded in one patient in Group R. There was no statistically significant difference between the groups with respect to complications ( $p>0.05)$.

\section{Discussion}

In this study, we found prolongations in QT, QTc, QTd, and QTcd values in thoracic epidural bupivacaine and ropivacaine groups in various phases. These prolongations did not cause any clinical signs related to ventricular conduction abnormalities during the study period. Even though we excluded the patients with conduction abnormalities, we estimated that ropivacaine could be a good alternative to bupivacaine in patients with a high incidence of ventricular arrhythmias. Similarly, a previous study performed by Lefrant et al. (7) revealed that ventricular electrophysiological variables were less altered with ropivacaine than with bupivacaine. Ropivacaine was less cardiotoxic than bupivacaine in terms of ventricular conduction, despite a $50 \%$ larger dose of ropivacaine in their study. In the study by Reiz et al. (13), the cardiotoxicity of ropivacaine was evaluated compared with bupivacaine and lidocaine. The prolongation of the QRS interval was considered as

Table 2. Corrected QT (QTc) values during epidural anaesthesia, induction of anaesthesia, and double-lumen tube insertion. Data are presented as median (minimum-maximum) for both groups.

\begin{tabular}{|c|c|c|c|c|c|}
\hline & \multicolumn{2}{|c|}{ Group B $(n=15)$} & \multicolumn{2}{|c|}{ Group R ( $n=15)$} & \multirow[b]{2}{*}{$p^{\S}$} \\
\hline & Median (Min-Max) & $p^{\pi}$ & Median (Min-Max) & $\mathbf{p}^{\pi}$ & \\
\hline QTc1 & $414(390-440)$ & & $413(380-440)$ & & 0.604 \\
\hline QTc2 & $435(385-452)$ & 0.096 & $419(364-523)$ & 0.875 & 0.206 \\
\hline QTc3 & 417 (389-440) & 0.900 & $416(356-438)$ & 0.495 & 0.506 \\
\hline QTc4 & $431(399-465)$ & 0.093 & $396(370-459)$ & 0.222 & $0.044^{\star}$ \\
\hline QTc5 & $424(381-446)$ & 0.363 & $410(358-451)$ & 0.712 & 0.206 \\
\hline QTc6 & $414(378-445)$ & 0.330 & $402(358-444)$ & 0.132 & 0.340 \\
\hline QTc7 & $425(374-456)$ & 0.363 & $409(374-455)$ & 0.802 & 0.198 \\
\hline QTc8 & $447(406-463)$ & $0.003^{\dagger}$ & $439(393-502)$ & $0.001^{\dagger}$ & 0.803 \\
\hline QTc9 & $437(410-491)$ & $0.003^{\dagger}$ & $426(395-482)$ & 0.033 & 0.245 \\
\hline QTc10 & 435 (414-475) & $0.004^{\dagger}$ & 416 (367-466) & 0.244 & $0.046^{*}$ \\
\hline
\end{tabular}

$\mathrm{p}^{\text {ๆ: }}$ Friedman test result, $\mathrm{p}^{\S}$ : Mann-Whitney $\mathrm{U}$ test result, ${ }^{\dagger}$ : statistical significance from baseline $(p<0.05),{ }^{*} p<0.05$ : statistical significance between groups 
Table 3. Results of QT dispersion (QTd) during epidural anaesthesia, induction of anaesthesia, and double-lumen tube insertion. Data are presented as median (minimummaximum) for both groups.

\begin{tabular}{|lccc|}
\hline & $\begin{array}{c}\text { Group B (n=15) } \\
\text { Median (Min-Max) }\end{array}$ & $\begin{array}{c}\text { Group R (n=15) } \\
\text { Median (Min-Max) }\end{array}$ & p \\
\hline QTd1 & $24.4(17.4-38.0)$ & $17.6(12.8-34.9)$ & $0.014^{\star}$ \\
OTd2 & $28.8(12.0-37.6)$ & $24.0(9.6-41.1)$ & 0.221 \\
OTd3 & $28.4(11.2-55.6)$ & $24.0(18.9-38.3)$ & 0.836 \\
QTd4 & $22.8(9.0-36.0)$ & $22.6(14.0-38.0)$ & 0.724 \\
OTd5 & $23.2(14.8-35.6)$ & $20.9(15.9-86.3)$ & 0.693 \\
QTd6 & $26.8(7.9-38.4)$ & $22.2(14.5-30.2)$ & $0.024^{\star}$ \\
OTd7 & $20.6(8.4-40.8)$ & $20.7(9.4-34.9)$ & 0.836 \\
OTd8 & $25.2(15.9-59.6)$ & $23.7(14.5-40.7)$ & 0.407 \\
OTd9 & $25.2(17.6-50.0)$ & $22.6(14.2-28.5)$ & 0.059 \\
OTd10 & $19.6(12.0-29.2)$ & $20.9(14.4-46.0)$ & 0.383 \\
\hline *p<0.05: statistical significance between groups. & \\
\hline
\end{tabular}

a measure of electrophysiological toxicity by the authors. The cardiac depression ratio was 4:3:1, whereas the proportion of electrophysiological toxicity was 15:6.7:1 (bupivacaine:ropiv acaine:lidocaine) in that study. In our study, the QTc interval after LA injection was longer in patients receiving bupivacaine than in those receiving ropivacaine. It might show that thoracic epidural LA administration, particularly bupivacaine, may induce the prolongation of QTc durations, which may trigger serious arrhythmia during anaesthetic course.

The changes in autonomic nervous system activity can directly influence the cardiac conduction systems, causing variations in the QTc interval, and may confuse the clinical evaluation of cardiac repolarisation time (14). Regional anaesthesia, particularly TEA, have cardiac effects due to blockade of the cardiac sympathetic innervations, but additional effects from bupivacaine absorbed systemically have not been ruled out. At a higher plasma concentration, LA might be subjected to systemic absorption during regional anaesthesia in humans. Significant cardiac electrophysiological and haemodynamic effects could occur due to a high LA plasma concentration. These effects may enhance the susceptibility to reentrant arrhythmias in predisposed patients $(15,16)$. In our study, we observed QTc interval prolongation in thoracic epidural ropivacaine and bupivacaine groups despite the sympathetic blockage. In TEA, the serum LA level might be increased after thoracic epidural administration. This situation might have contributed to prolongation of the QTc interval.

The impact of propofol and fentanyl on the QT interval remains controversial. Propofol-induced prolongation of the QTc interval has been observed in various studies (17-19). In the present study, the QT interval was prolonged after propofol injection, but we did not observe any QTc prolongation with propofol usage. Wilton et al. (20) concluded that fentanyl did not prolong QTc duration in their trial. We also did not detect any QTc prolongation with fentanyl. The QTd and QTcd values at the $1^{\text {st }} \min$ of propofol injection were longer in the patients receiving epidural bupivacaine. Our results did not demonstrate any clear effect of propofol on QT parameters.

Michaloudis et al. (21) assessed the effects of midazolam followed by either vecuronium or atracurium on the QT interval. They did not observe the prolongation of QT interval following vecuronium administration in patients with normal QT. Nevertheless, we found statistically significant prolongation of the QT interval after vecuronium in both groups.

The cardiovascular response to tracheal intubation is the consequence of augmented plasma noradrenaline levels during laryngoscopy and immediately after intubation. Scheinin et al. (22) found a close correlation between plasma noradrenaline concentration and the QTc interval. In the present study, QT and QTc durations were increased compared with basal values during laryngoscopy and in the various phases of the post-intubation period in the groups. The prolongation of the QTc intervals during laryngoscopy was significant in both groups. The QTc interval was also longer in the bupivacaine group than in the ropivacaine group at the $5^{\text {th }} \mathrm{min}$ of endobronchial intubation.

The effect of sevoflurane on the QT interval is debatable. Sevoflurane, isoflurane, and desflurane have been reported to prolong QTd, QTc, and QTcd (23). Nevertheless, according to Kazanci et al. (24), desflurane and sevoflurane showed no significant difference with respect to QTc and QTcd. In our study, the QTc interval was longer in the bupivacaine group at the $5^{\text {th }}$ min of intubation, in other words, the $5^{\text {th }}$ min of sevoflurane anaesthesia.

We observed stable cardiovascular haemodynamics, which are one of the beneficial aspects of epidural anaesthesia in both groups receiving TEA combined with GA. Even though the differences in MAP within and between the groups were statistically significant, all values were within the normal range. HR values were also within the normal limits. The haemodynamic complications such as ventricular extrasystoles, bradycardia, and hypotension were observed without any clinical effects.

Abnormal serum electrolyte levels may affect cardiac conduction. Changes in extracellular potassium, calcium, and magnesium levels can alter the cardiac action potential. These changes may precipitate potentially life-threatening dysrhythmias (25). Although the differences in preoperative potassium levels were statistically significant, all levels were within the normal range in our study. Therefore, there was no electrolyte imbalance that could alter QT intervals in this study. A limitation in this study is that usually QT dispersion is calculated using the difference between the shortest and longest QT intervals in a 2-min rhythm recording, but we used a single ECG recording to calculate QT dispersion. In conclusion, the QTc, QTd, and QTcd values were slightly longer with bupivacaine compared with ropivacaine in various phases of TEA combined with GA. It could be assumed that ropivacaine is a good alternative to bupivacaine in patients with abnormalities of ventricular conduction.

Ethics Committee Approval: Ethics committee approval was received from Atatürk Chest Diseases and Thoracic Surgery Education and Research Hospital. 
Informed Consent: Written informed consent was received from the participants of this study.

Peer-review: Externally peer-reviewed.

Author contributions: Concept - H.S., Ö.G., Ç.S.D., E.Ş.; Design E.S., Ö.G., H.S.; Supervision - H.S., Ö.G., Ç.S.D., E.Ş., A.A.; Resource - H.S., Ö.G.; Materials - XH.S., Ö.G.; Data Collection\&/or Processing H.S., Ö.G., A.A.; Analysis\&/or Interpretation - H.S., Ö.G., A.A., A.Y., E.K.; Literature Search - H.S., Ö.G., A.A.; Writing H.S., A.A., A.Y., E.K.; Critical Reviews - H.S., Ö.G., A.A., A.Y., E.K, E.Ş., Ç.S.D.

Conflict of Interest: No conflict of interest was declared by the authors.

Financial Disclosure: The authors declared that this study received no financial support.

\section{References}

1. Campos JH. Fast track in thoracic anesthesia and surgery. Curr Opin Anaesthesiol 2009;22:1-3. [CrossRef]

2. Xu Y, Tan Z, Wang S, Shao H, Zhu X. Effect of thoracic epidural anesthesia with different concentrations of ropivacaine on arterial oxygenation during one-lung ventilation. Anesthesiology 2010;112:1146-54. [CrossRef]

3. Freise H, Van Aken HK. Risks and benefits of thoracic epidural anaesthesia. Br J Anaesth 2011;107:859-68. [CrossRef]

4. Senturk M. Acute and chronic pain after thoracotomies. Curr Opin Anaesthesiol 2005;18:1- 4. [CrossRef]

5. Moller R, Covino BG. Cardiac electrophysiologic properties of bupivacaine and lidocaine compared with those of ropivacaine, a new amide local anesthetic. Anesthesiology 1990;72:322-9. [CrossRef]

6. Pitkanen M, Feldman HS, Arthur GR, Covine BG. Chronotropic and inotropic effects of ropivacaine, bupivacaine, and lidocaine in the spontaneously beating and electrically paced isolated, perfused rabbit heart. Reg Anesth 1992;17:183-92.

7. Lefrant JY, de La Coussaye JE, Ripart J, Muller L, Lalourcey L, Peray PA, et al. The comparative electrophysiologic and hemodynamic effects of a large dose of ropivacaine and bupivacaine in anesthetized and ventilated piglets Anesth Analg 2001;93:1598-605. [CrossRef]

8. Mazoit JX, Cao LS, Samii K. Binding of bupivacaine to human serum proteins, isolated and isolated alpha1-acid glycoprotein:differences between the two enantiomers are partly due to cooperativity. J Pharmacol Exp Ther 1996;256:109-15

9. Takmaz SA, Uysal HY, Inan N, Kaptan Z, Basar H. Effects of right and left stellate ganglion block on blood pressure and QT-QTc intervals in patients with primary Raynaud's phenomenon. Turk J Med Sci 2012;42:89-94.

10. Scott DB, Lee A, Fagan D, Bowler GMR, Bloomfield P, Lundh R. Acute toxicity of ropivacaine compared with that of bupivacaine.
Anesth Analg 1989:69:563-9. [CrossRef]

11. Schwartz PJ, Wolf S. QT interval prolongation as predictor of sudden death in patients with myocardial infarction. Circulation 1978;57:1074-7. [CrossRef]

12. Bazett HC. An analysis of the time-relation of electrocardiograms. Heart 1929;7:353-67.

13. Reiz S, Häggmark S, Johansson G, Narh S. Cardiotoxicity of ropivacaine - a new amide local anaesthetic agent. Acta Anaesthesiol Scand 1989;33:93-8. [CrossRef]

14. Magnano AR, Holleran S, Ramakrishnan R, Reiffel JA, Bloomfield DM. Autonomic nervous system influences on QT interval in normal subjects. J Am Coll Cardiol 2002;39:1820-6. [CrossRef]

15. Hotvedt R, Platou ES, Refsum H. Electrophysiological effects of thoracic epidural analgesia in the dog heart in situ. Cardiovasc Res 1983;17:259-66. [CrossRef]

16. Hotvedt R, Platou ES, Refsum H. Effects of thoracic epidural analgesia on cardiovascular function and plasma concentration of free fatty acids and catecholamines in the dog. Acta Anaesthesiol Scand 1984;28:132-7. [CrossRef]

17. Irie $T$, Kaneko $Y$, Nakajima T, Saito A. QT interval prolongation and torsade de pointes induced by propofol and hypoalbuminemia. Int Heart J 2010;51:365-6. [CrossRef]

18. McConachie I, Keaveny JP, Healy TE, Vohra S, Million L. Effect of anaesthesia on the QT interval. Br J Anaesth 1989;63:558-60. [CrossRef]

19. Kim DH, Kweon TD, Nam SB, Han DW, Cho WY, Lee JS, et al. Effects of target concentration infusion of propofol and tracheal intubation on QTc interval. Anaesthesia 2008;63:1061-4. [CrossRef]

20. Wilton NC, Hantler CB. Congenital long QT syndrome:changes in QT interval during anesthesia with thiopental, vecuronium, fentanyl and isoflurane. Anesth Analg 1987;66:357-60. [CrossRef]

21. Michaloudis DG, Kanakoudis FS, Xatzikraniotis A, Bischiniotis TS. The effects of midazolam followed by administration of either vecuronium or atracurium on the QT interval in humans. Eur $\mathrm{J}$ Anaesthesiol 1995;12:577-83.

22. Scheinin B, Lindgren $L$, Randell $T$, Scheinin H, Scheinin M. Dexmedetomidine attenuates sympathoadrenal responses to tracheal intubation and reduces the need for thiopentone and peroperative fentanyl. Br J Anaesth 1992;68:126-31. [CrossRef]

23. Aypar E, Karagoz AH, Ozer S, Celiker A, Ocal T. The effects of sevoflurane and desflurane anesthesia on QTc interval and cardiac rhythm in children. Paediatr Anaesth 2007;17:563-7. [CrossRef]

24. Kazanci D, Unver S, Karadeniz U, lyican D, Koruk S, Yilmaz MB, et al. A comparison of the effects of desflurane, sevoflurane and propofol on QT, QTc, and P dispersion on ECG. Ann Card Anaesth 2009;12:107-12. [CrossRef]

25. Diercks DB, Shumaik GM, Harrigan RA, Brady WJ, Chan TC. Electrocardiographic manifestations: electrolyte abnormalities. J Emerg Med 2004;27:153-60. [CrossRef] 